\title{
JUVENTUDE E ENSINO MÉDIO INTEGRADO: POR UM DIÁLOGO POSSÍVEL ENTRE A EDUCAÇÃO AMBIENTAL E A EDUCAÇÃO PROFISSIONAL
}

\author{
J. L. PAULA ${ }^{1}$ e A. L. S. HENRIQUE ${ }^{2}$ \\ Instituto Federal de Educação, Ciência e Tecnologia do Rio Grande de Norte \\ ana.henrique@ifrn.edu.br
}

Artigo submetido em julho/2015 e aceito em julho/2015

DOI: $10.15628 /$ holos.2015.3186

\section{RESUMO}

O presente artigo versa sobre a relação entre gestão ambiental, políticas públicas e educação profissional. Partindo do questionamento: Como as políticas públicas interferem no processo de gestão ambiental e em que medida essa relação repercute na educação profissional na atualidade? Objetivamos identificar a repercussão na educação profissional, da interferência das políticas públicas no processo de gestão ambiental. Para tanto, realizamos um breve levantamento bibliográfico acerca dessa temática, conceituando-a e contextualizando-a, além de analisarmos o conteúdo/respostas atribuídas a um questionário aplicado a um Ecólogo, Consultor
Ambiental. Como referencial utilizamos autores como: AZEVEDO (2011), BRASIL (2007), CAVALCANTI (1997) GUTIÉRREZ e PRADO (2008), LANNA (1995), LEFF (2010), LOUREIRO (2008), entre outros, bem como algumas legislações regulamentadoras da temática. Ao final da pesquisa, identificamos que as políticas públicas voltadas para área ambiental se configuram como um instrumento de gestão ambiental, enquanto a educação (inclusive profissional), representa outro instrumento estratégico para gestão ambiental. Portanto, concluímos que educação, políticas públicas e gestão ambiental estão intimamente conectados.

PALAVRAS-CHAVE: Gestão Ambiental, Educação Ambiental, Políticas Públicas, Educação Profissional.

\section{YOUTH AND INTEGRATED HIGH SCHOOL: FOR A POSSIBLE DIALOGUE BETWEEN THE ENVIRONMENTAL EDUCATION AND VOCATIONAL EDUCATION}

\begin{abstract}
This article deals with the relationship between environmental management, public policy and professional education. Based on the question: How public policies interfere in the environmental management process and to what extent this relationship is reflected in education today? We aim to identify the impact in education, the interference of public policies in the environmental management process. Thus, we performed a brief literature on this theme, conceptualizing it and contextualizing it, and analyze content / assigned responses to a questionnaire applied to a Ecologist, Environmental Consultant. As a reference
\end{abstract}

authors use as Azevedo (2011), BRAZIL (2007), Cavalcanti (1997), GUTIERREZ and PRADO (2008), Lanna (1995), LEFF (2010), Loureiro (2008), among others, as well as some laws regulatory of the theme. At the end of the study, we identified that public policies related to environmental area are configured as an environmental management tool, while the education (including vocational), is another strategic tool for environmental management. We therefore conclude that education, public and environmental management policies are closely connected.

KEYWORDS: Environmental Management, Environmental Education, Public Policy, Professional Education. 


\section{INTRODUÇÃO}

Os problemas ambientais se constituem como desafios para a sociedade. Não surgiram hoje, mas vêm se acumulando ao longo de séculos. Tal fato nos remete a Braverman (1977), que tecendo considerações sobre a definição de trabalho, pontua:

Todas as formas de vida mantêm-se em seu meio ambiente natural; assim é que todos desempenham atividades com o propósito de apoderar-se de produtos naturais em seu próprio proveito. [...] Assim, a espécie humana partilha com as demais atividade de atuar sobre a natureza de modo a transformá-la para melhor satisfazer suas necessidades. (BRAVERMAN, 1977, p. 49)

Diante dessa fala, vislumbramos a atuação sobre a natureza como um processo natural de todas as formas de vida, embora, a capacidade de transformar um produto natural em um novo/outro produto que atenda a necessidades diversas, seja humana. E é justamente no ato de apoderar-se em larga escala e transformar a natureza para o bem-estar individual ao longo dos séculos que tem repercutido a ação humana sobre a situação ambiental, agravando seu estado inegavelmente.

Beck (1992, apud LEIS, 1997) nos diz que o somatório da enorme quantidade de tecnologias derivadas da ciência moderna resultou em uma pouco confiável sociedade de risco. Entendemos com isso que a "sociedade de risco" foi constituída em meio aos resíduos advindos da "evolução humana", científica e tecnológica.

Diante desse contexto, cruzar os braços e esperar que os outros façam algo, com o argumento de que eles são os maiores responsáveis pelos danos ao meio, denuncia a crise pessoal na qual estamos afundando em relação aos nossos valores. Que novos valores temos construído ao longo da vida para o total desrespeito à natureza e à própria vida? Refletir, então, sobre esse universo, seus avanços e retrocessos é fundamental.

Sendo assim, nos dedicamos, neste texto, a refletir sobre como as políticas públicas interferem no processo de gestão ambiental e em que medida essa relação repercute na educação profissional na atualidade, buscando a essa interferência. Para isso, realizamos um breve levantamento bibliográfico no qual obtemos suporte teórico-conceitual imprescindível à discussão, tendo em vista que, conforme nos diz Cervo e Bervian (1976, apud PINTO, 2010), qualquer tipo de pesquisa, independente da área do conhecimento a qual pertença, supõe e exige pesquisa bibliográfica prévia, quer para o levantamento da situação em questão, quer para a fundamentação teórica.

Após a pesquisa bibliográfica, buscando identificar como a temática aqui abordada se aplica na prática atualmente, fomos a campo, utilizando um questionário, com perguntas abertas, como instrumento de coleta de dados. As respostas fornecidas ao questionário foram, então, discutidas à luz do referencial obtido pelo levantamento bibliográfico, conforme discorreremos ao longo deste artigo. 


\section{EDUCAÇÃO E GESTÃO AMBIENTAL MATERIALIZADAS NA EDUCAÇÃO PROFISSIONAL, AMPARADAS POR POLÍTICAS PÚBLICAS}

A questão ambiental vem ganhando cada vez mais espaço em meio à sociedade. Isso decorre da preocupação de alguns com o futuro da vida e sua qualidade.

Os danos prejudiciais à vida humana aumentam com o passar dos anos. Crescimento populacional, desenvolvimento das cidades, expansão do sistema produtor de mercadorias, rápido progresso científico entre outros, são fatores que geram inúmeras transformações no meio em que vivemos e repercutem sobre o meio ambiente.

A poluição, que provoca desequilíbrios no ecossistema natural gerando extinção de espécies animais e vegetais, atrelada ao empobrecimento do solo, assoreamento dos rios, aquecimento global e efeito estufa afetam diretamente a qualidade de vida no planeta. Na maioria das vezes, são desencadeados pela ação irrefletida do ser humano sobre a natureza, que a modifica em favor do seu benefício próprio imediato para maior comodidade e conforto. Tais problemas encontram alicerce no espírito altamente competitivo e não cooperativo da sociedade, instigado pelo sistema econômico dominante que prega o consumismo exacerbado, conduzindo à destruição dos recursos naturais, como afirma Branco (2003).

Frente a esse panorama, percebemos a complexidade da situação ambiental com a qual nos deparamos. Não foram ações pontuais que eclodiram formando os problemas vivenciados hoje, mas diversos elementos/fatores imbricados que se coadunam, forjando o contexto ambiental do século XXI, responsabilidade de todos nós.

$\mathrm{Na}$ tentativa de compreender as mudanças globais do nosso tempo e preparar novas mentalidades e habilidades capazes de buscar caminhos para um futuro sustentável, conforme nos diz Leff (2010), a questão ambiental adentra no cenário político, científico e educacional - cenários intimamente relacionados e que requerem nossa atenção, por isso, iremos pormenorizar.

\subsection{Educação Ambiental e sua Política}

Inserida na temática proposta por este artigo, no campo educacional, nos reportamos à Educação Ambiental, que foi oficializada por meio da Lei 9.795/99 que instituiu a Política Nacional de Educação Ambiental (PNEA), e em seus primeiros artigos é assim descrita:

Art. 1ํㅡㄹ Entendem-se por educação ambiental os processos por meio dos quais o indivíduo e a coletividade constroem valores sociais, conhecimentos, habilidades, atitudes e competências voltadas para a conservação do meio ambiente, bem de uso comum do povo, essencial à sadia qualidade de vida e sua sustentabilidade.

Art. 2으 A educação ambiental é um componente essencial e permanente da educação nacional, devendo estar presente, de forma articulada, em todos os níveis e modalidades do processo educativo, em caráter formal e não-formal. (BRASIL, 1999).

Essa defesa demanda uma educação ambiental articulada em todos os níveis e modalidades do processo educativo, seja ele escolarizado ou não. Para tal, implica-se que sejam atendidas as especificidades regionais e locais, conforme orienta o art. 4으, inciso VII da Lei 9.795/99 (BRASIL, 1999). 
O art. 9o, inciso IV, da lei supracitada é ainda mais específico, e estabelece o desenvolvimento da educação ambiental no âmbito do currículo da Educação Profissional, como tema transversal. Para tanto, o art. 10, dessa mesma lei, pressupõe que a educação ambiental seja desenvolvida como uma prática educativa integrada, contínua e permanente, e acrescenta/define em seu parágrafo $3^{\circ}$ que: "Nos cursos de formação e especialização técnico-profissional, em todos os níveis, deve ser incorporado conteúdo que trate da ética ambiental das atividades profissionais a serem desenvolvidas" (BRASIL, 1999).

A inserção da temática ambiental nos cursos voltados à educação profissional (para atender a proposta de educação ambiental dos profissionais em formação) ocorre, pois a própria lei (no 9.795/99) estabelece como linha de atuação da PNEA a capacitação de recursos humanos, o desenvolvimento de estudos, pesquisas e experimentações e a produção e divulgação de material educativo, bem como, acompanhamento e avaliação dessas ações (art. 8o da Lei no 9.795/99).

Essa vinculação da educação ambiental ao processo de formação/educação profissional se concretiza pela indubitável relação com a formação humana, ética, cidadã, imprescindível ao trabalho em sociedade e/ou exercício da profissão. Tal vinculação está expressa, por exemplo, no Projeto Pedagógico de Curso de Graduação de Tecnologia em Gestão Ambiental quando cita como característica do perfil de egresso do curso "ter atitude ética no trabalho e no convívio social, compreender os processos de socialização humana em âmbito coletivo e perceber-se como agente social que intervém na realidade" (IFRN, 2012). Nesse sentido, fazemos menção à fala de Loureiro (2008, p.93), quando nos diz que "é fundamental associarmos processos educativos formais às demais atividades sociais [...], buscando-se o conhecimento, a reflexão e a ação concreta sobre o ambiente em que se vive".

No entanto, a PNEA não se mostrou suficiente. Para suprir as carências da emergência do aprofundamento sobre a complexa problemática que se instala (e se agrava com o passar dos anos) no tangente ao meio ambiente, foram elaboradas as Diretrizes Curriculares Nacionais para a Educação ambiental (DCNEA). De acordo com essas diretrizes,

O atributo "ambiental" na tradição da Educação Ambiental brasileira e latinoamericana [...] se constitui em elemento estruturante que demarca um campo político de valores e práticas, mobilizando atores sociais comprometidos com a prática político-pedagógica transformadora e emancipatória capaz de promover a ética e a cidadania ambiental. (BRASIL, 2012, p.1-2, grifo do autor).

Então, instituídas pelo Conselho Nacional de Educação (CNE), por meio da Resolução no 2 de 15 de junho de 2012, as Diretrizes Curriculares Nacionais para a Educação Ambiental trazem em seu texto características conceituais e pedagógicas, com esclarecimentos consoantes às particularidades da temática e sua implementação nos diferentes níveis e modalidades de educação, segundo exposto em Brasil (2012). Essas diretrizes respeitam a Lei de Diretrizes e Bases da Educação Nacional (LDB) e a obedecem, tendo em vista que uma das finalidades da educação (estabelecidas pela LDB/1996) é a preparação para o exercício da cidadania, perpassando pela compreensão do ambiente natural e social, o conhecimento do mundo físico e natural e o entendimento do ser humano e do meio em que vive, ao longo da formação do sujeito/educando.

Vislumbramos, nesse contexto, que tal educação deve ultrapassar os muros da escola e a responsabilidade do Poder Público. Ela pressupõe o engajamento de todos que compõem a sociedade, como descrito no art. 3으 da lei supracitada. 
Art. 3ํ Como parte do processo educativo mais amplo, todos têm direito à educação ambiental, incumbindo:

I - ao Poder Público, nos termos dos arts. 205 e 225 da Constituição Federal, definir políticas públicas que incorporem a dimensão ambiental, promover a educação ambiental em todos os níveis de ensino e o engajamento da sociedade na conservação, recuperação e melhoria do meio ambiente;

II - às instituições educativas, promover a educação ambiental de maneira integrada aos programas educacionais que desenvolvem;

III - aos órgãos integrantes do Sistema Nacional de Meio Ambiente - Sisnama, promover ações de educação ambiental integradas aos programas de conservação, recuperação e melhoria do meio ambiente;

IV - aos meios de comunicação de massa, colaborar de maneira ativa e permanente na disseminação de informações e práticas educativas sobre meio ambiente e incorporar a dimensão ambiental em sua programação;

V - às empresas, entidades de classe, instituições públicas e privadas, promover programas destinados à capacitação dos trabalhadores, visando à melhoria e ao controle efetivo sobre o ambiente de trabalho, bem como sobre as repercussões do processo produtivo no meio ambiente;

VI - à sociedade como um todo, manter atenção permanente à formação de valores, atitudes e habilidades que propiciem a atuação individual e coletiva voltada para a prevenção, a identificação e a solução de problemas ambientais. (BRASIL, 1999)

Para que isso se efetue na prática, de acordo com o art. 7으, a PNEA envolve: órgãos e entidades integrantes do Sistema Nacional de Meio Ambiente (Sisnama); instituições educacionais públicas e privadas dos sistemas de ensino; órgãos públicos da União, dos Estados, do Distrito Federal e dos Municípios; e, organizações não-governamentais com atuação em educação ambiental (BRASIL, 1999).

No entanto, apesar da Lei 9.795 datar de 27 de abril de 1999, somente em junho de 2003, foi instituído seu Órgão Gestor, segundo BRASIL (2003). O referido órgão foi composto pelo Ministério do Meio Ambiente (MMA) e o Ministério da Educação (MEC), tendo como missão materializar a Lei no 9.795/1999 (PNEA) e o Decreto no 4.281/2002 (que cria o Comitê Assessor). Ao Comitê Assessor (criado antes do Órgão Gestor), por sua vez, cabe assessorar o Órgão Gestor, configurando-se como uma instância de controle social-ambiental-educacional dessa política pública.

Dentre as atribuições gerais do Órgão Gestor, conforme o art. 15 da PNEA, estão:

Art. 15. São atribuições do órgão gestor:

I - definição de diretrizes para implementação em âmbito nacional;

II - articulação, coordenação e supervisão de planos, programas e projetos na área de educação ambiental, em âmbito nacional;

III - participação na negociação de financiamentos a planos, programas e projetos na área de educação ambiental. (BRASIL, 1999).

Diante dessas atribuições, ressaltamos a coordenação e supervisão de programas, tendo em vista a existência do Programa Nacional de Educação Ambiental (ProNEA), já em sua 3a edição.

O ProNEA hoje é elemento constitutivo da política pública de educação ambiental brasileira, muito embora sua versão original date de 1994, resultando do Projeto de Lei no 3.792/93 
para a formulação de uma Política Nacional de Educação Ambiental. Podemos dizer com isso que o ProNEA foi precursor da Lei no 9.795/1999 (PNEA) e, depois se tornou um instrumento da política pública na área que atende.

Dentre objetivos desse instrumento (ProNEA) de política pública para educação ambiental, listados em Brasil (2005), citamos: promover processos de educação ambiental (também integrados a programas de conservação, recuperação e melhoria do meio ambiente); fomentar processos de formação continuada referente a essa temática; contribuir com a organização de grupos que atuem em programas de intervenção em educação ambiental; promover campanhas nos meios de comunicação de massa; criar espaços de debates garantindo a participação da população nos processos decisórios, entre outros instrumentos.

Além destes, o ProNEA tem ainda como objetivo "produzir e aplicar instrumentos de acompanhamento, monitoramento e avaliação de suas ações, considerando a coerência com suas diretrizes e princípios" (BRASIL, 2005, p. 40-41) - indispensáveis à qualquer política pública.

Vale ressaltar ainda que o referido Programa concebe a educação ambiental como um fundamental instrumento à gestão ambiental. E para nós, não há como escapar dessa concepção, pois percebemos a educação ambiental como elemento estratégico no processo de gestão ambiental, sobretudo quando nos referimos ao campo da Educação Profissional. E como nos dizem Gutiérrez e Prado (2008):

\footnotetext{
A educação que se dá ao longo do processo é o que torna possível a apropriação de sentido, a geração de relações significativas e a ativação de forças e potencialidades necessárias a todo grupo que está em processo. (GUTIÉRREZ e PRADO, 2008, p. 53)
}

Sendo assim, consciência social, valor da diversidade ecológica, reconhecimento de prioridades, descentralização econômica, gestão participativa e aproximação entre o local e global, adentram a formação cidadã dos sujeitos sociais. Todos esses são elementos inseridos no universo da educação ambiental, bem como conquistas fundamentais à sustentabilidade, alvo da gestão ambiental.

Ressaltamos ainda que os elementos citados encontram morada nos fundamentos teóricopráticos da Educação Profissional no tangente a formação, por exemplo, de técnicos em Controle Ambiental e tecnólogos em Gestão Ambiental. Isso se justifica, de acordo com IFRN (2012), tendo em vista que os cursos ofertados para as qualificações mencionadas se propõem a formar profissionais capazes de dominar conhecimentos científicos e tecnológicos referentes ao meio ambiente que lhes permitam planejar e intervir na sociedade para prevenção, mitigação e/ou recuperação ambiental. Portanto, pela Educação Profissional também se materializam instrumentos de gestão ambiental, ao passo que a partir dessa modalidade de ensino formam-se recursos humanos aptos para tal.

\subsection{Gestão Ambiental e Políticas Públicas}

O ProNEA em seu documento base prevê linhas de ação e estratégias como "estímulo à inserção da educação ambiental nas etapas de planejamento e execução de ações relacionadas a: gestão de recursos naturais [...]; preservação da biodiversidade;" (BRASIL, 2005, p.44) entre outras. Percebemos na proposição dessa estratégia de atuação estreita ligação com o processo de gestão 
ambiental, em profunda afinidade com o perfil de egresso do curso de Tecnologia em Gestão Ambiental do IFRN.

Nesse sentido, recordamos a definição que Lanna (1995) atribui à gestão ambiental, ao dizer que se trata de um processo de articulação das ações dos diferentes agentes sociais que interagem visando garantir, por meio de diretrizes previamente definidas, adequações dos meios de exploração dos recursos ambientais, econômicos e socioculturais às especificidades do meio ambiente. Vemos nas palavras desse autor que o processo de gestão ambiental não se dá de forma individualizada, isolada e/ou descontextualizada, mas sim, como fruto de uma articulação que se vincula também a demanda socioambiental. Tal demanda se projeta, por sua vez, sobre as políticas, públicas, uma vez entendidas como espaços centrais de discussão e decisão sobre os interesses e/ou problemas locais, regionais ou globais.

No tocante às políticas públicas, recorremos à colocação de Brasil (2007), alicerçada em autores como Bruguê e Goma (1999), Subirats (1998) e Rua (1998), quando nos diz que:

[...] as políticas públicas constituem espaços centrais de mediação e de gestão dos conflitos sociais no contexto das sociedades contemporâneas - complexas, plurais e diferenciadas. Resultam da atividade política, em campos ou arenas específicas, dos diferentes atores sociopolíticos que, a partir de suas demandas, pressões e atuações, procuram influir na formação da agenda e no curso das intervenções governamentais. (BRASIL, 2007, p. 115-116).

Centrando-nos sobre o aspecto da compreensão das políticas públicas enquanto "espaços centrais de mediação e de gestão de conflitos", pontuado por Brasil (2007, p. 115), trazemos ainda a definição atribuída por Azevedo (2011) que acrescenta a esse respeito.

[...] constituem o espaço por meio do qual as sociedades complexas (capitalistas, modernas, urbano-industriais, como desejemos nomeá-las) buscam solucionar os graves problemas e os grandes desafios tecidos na dinâmica da realidade social injusta e desigual. Isto, por seu turno, se processa por meio da construção de referenciais, definidos como um conjunto de matrizes cognitivas e normativointelectuais, que determinam os instrumentos e meios com os quais as sociedades atuam sobre elas próprias (que tomam o feitio das políticas públicas) e os espaços e sentidos que orientam as relações/interações entre os grupos sociais. (AZEVEDO, 2011, p. 413).

Inserida nessa perspectiva de definição, Azevedo (2011) situa três dimensões imbricadas no seio das políticas públicas: a cognitiva (conhecimento técnico-científico a respeito da problemática em questão), a instrumental (referencial constituído por dados técnicos, princípios, valores, normas etc.) e a normativa (relação entre políticas, valores e práticas).

Respeitando essa organização, Cavalcanti, na obra que organizou juntamente com outros autores em 1997, já defendia uma política de gestão ambiental com ações voltadas ao reconhecimento da limitação ecológica. Para esse autor,

Política de governo para a sustentabilidade significa uma orientação das ações públicas motivadas pelo reconhecimento da limitação ecológica fundamental dos recursos (matéria e energia) sem os quais nenhuma atividade humana pode se realizar. 
[...] Uma política comprometida com a sustentabilidade tem que desencorajar aquilo que cause ameaças à saúde de longo prazo do ecossistema e a base biofísica da economia, tal como ineficiência, lixo, poluição, uso excessivo ou garimpo de recursos renováveis, dissipação de recursos esgotáveis. (CAVALCANTI, 1997, p.30).

De acordo com Cavalcanti (1997), outro aspecto que requer a atenção das políticas públicas no ramo da sustentabilidade, como elemento necessário à gestão ambiental, são os hábitos de consumo e estilo de vida, que devem respeitar parâmetros de prudência ecológica - o que adentra a proposta de desencorajamento daquilo que cause ameaça ao ecossistema. Esses aspectos podem ser contemplados tanto por via das políticas de educação ambiental, quanto pelas políticas de meio ambiente, pois ambas buscam a gestão ambiental. Ainda no tocante ao consumo, Sorrentino (2008) defende o comprometimento das políticas públicas com a inclusão na diversidade e com o questionamento dos valores e obviedades da sociedade de consumo que, por sua vez, ocorreria via estímulo ao debate e à busca de respostas para a melhoria da qualidade de vida.

E em se tratando de políticas públicas, a Política Nacional do Meio Ambiente (PNMA) adentra a discussão como indispensável elemento de gestão ambiental, uma vez que tem por objetivo geral a preservação, melhoria e recuperação da qualidade ambiental propícia à vida, conforme descreve seu art. 20 (BRASIL, 1981). Inserido nesse objetivo, visa como um de seus princípios a educação ambiental em todos os níveis de ensino (e destacamos sua aplicabilidade no contexto da Educação Profissional), inclusive a educação da comunidade, objetivando capacitá-la para participação ativa na defesa do meio ambiente.

Tal Política foi sancionada a partir da Lei no 6.938, de 31 de agosto de 1981 (BRASIL, 1981), sofrendo novas redações, inclusões e vetos ao longo dos anos que se sucederam. Mas, até hoje se mantém como eminente instrumento de gestão ambiental em nosso país.

Essa Lei constitui ainda o Sistema Nacional do Meio Ambiente (SISNAMA), integrado pelos órgãos e entidades da União, dos Estados, do Distrito Federal, dos Municípios e pelas Fundações instituídas pelo Poder Público, responsáveis pela proteção e melhoria da qualidade ambiental. E institui também o Conselho Nacional do Meio Ambiente (CONAMA), órgão este (colegiado representativo de cinco setores: órgãos federais, estaduais e municipais, setor empresarial e sociedade civil) consultivo e deliberativo do SISNAMA, abarcando dentre suas responsabilidades, estabelecer sistemática de monitoramento, avaliação e cumprimento das normas ambientais.

Nesse universo, conforme o art. 4ํ da Lei no 6.938/81 (PNMA), um dos aspectos visados é "a compatibilização do desenvolvimento econômico-social com a preservação da qualidade do meio ambiente e do equilíbrio ecológico" (BRASIL, 1981). Portanto, faz-se necessário estar atento ao fluxo de recursos naturais investido na expansão da economia para que se deixe de exaurir as fontes e volte-se à busca pelo equilíbrio ecológico.

Partindo dessa perspectiva, a PNMA conceitua (em seu art. 3ㅇ) o que entende por meio ambiente, degradação da qualidade ambiental, poluidor e recursos ambientais. E com base na conceituação que define, estabelece no art. 9으, Lei no 6.938/81 (BRASIL, 1981), como seus instrumentos de gestão ambiental: padrões de qualidade ambiental; zoneamento ambiental; avaliação de impactos ambientais; licenciamento e revisão de atividades poluidoras; criação de áreas de proteção ambiental; sistema nacional de informações sobre o meio ambiente; cadastro 
técnico federal de atividades e instrumentos de defesa ambiental; penalidades disciplinares à degradação ambiental; relatório de qualidade do meio ambiente; instrumentos econômicos como concessão florestal, seguro ambiental, entre outros instrumentos.

Assim, o Instituto Brasileiro do Meio Ambiente e dos Recursos Naturais Renováveis (IBAMA) e o Instituto Chico Mendes de Conservação da Biodiversidade (Instituto Chico Mendes) entram em cena, pois são os órgãos executores da PNMA, atualmente constituídos, e tem como função fazer valer a lei que dispõe sobre a Política Nacional do Meio Ambiente e suas diretrizes. Lembramos ainda que esses órgão são compostos por profissionais especialista em educação e/ou gestão ambiental, dentre eles, técnicos e tecnólogos na área, bem como ecólogos, geólogos e outros.

Mas, para somar-se ao processo de gestão ambiental, nosso país conta também com o Fundo Nacional do Meio Ambiente (FNMA), criado pela Lei no 7.797, de 10 de julho de 1989, cuja missão é contribuir para a implementação da PNMA, como agente financiador, por meio da participação social.

Esse Fundo Nacional, de acordo com seu art. 1ㅇ, tem como objetivo "desenvolver os projetos que visem ao uso racional e sustentável de recursos naturais, incluindo a manutenção, melhoria ou recuperação da qualidade ambiental no sentido de elevar a qualidade de vida da população brasileira" (BRASIL, 1989). Para desenvolver os projetos socioambientais em território nacional aprovados, o FNMA destina recursos públicos - hoje administrados pelo Ministério do Meio Ambiente. No entanto, define em seu texto base suas condições de investimento:

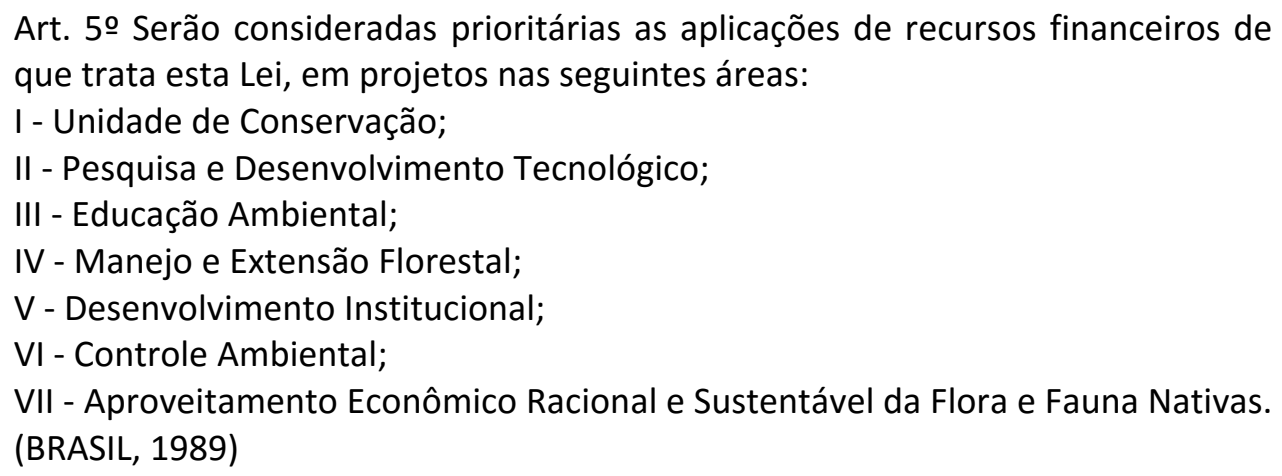

Mais uma vez tornamos à educação ambiental, elemento intrínseco ao processo de gestão ambiental, que perpassaria, até mesmo de forma subliminar, por todas as demais áreas, como projeto a PNEA. Mesmo assim, o MMA (através dos órgãos competentes para esses fins, formados por profissionais especialistas na área) avalia a viabilidade dos projetos apresentados e investe naqueles que atendem as prioridades nacionais.

Embora essas regulamentações legais/oficiais se disponham a abarcar todas as demandas relativas a problemas/soluções ambientais, na concretude de sua prática, surgem as lacunas. E são essas lacunas (que se apresentam durante o monitoramento e/ou avaliação das políticas) que precisam adentrar aos espaços de discussão para o planejamento, formulação e implementação de novas políticas públicas na área (bem como de seu monitoramento e avaliação). Isso, pois, nesse processo de avaliação deve ser levado em conta que "é necessário que as políticas de governo para o desenvolvimento sustentável sejam desenhadas no contexto de princípios éticos relativos ao bem-estar das gerações futuras e atuais" (CAVALCANTI, 1997, p.28). 
Então, se o desenvolvimento sustentável é de fato o foco das políticas públicas referentes à gestão ambiental, não se pode perder de vista o exercício da cidadania plena, comprometida eticamente com a qualidade ambiental e a justiça social, no presente. Do mesmo modo, precisa alicerçar a Educação Profissional na oferta de seus mais variados cursos, a fim de favorecer a construção e disseminação de conhecimentos científicos que fomentem estratégias alternativas para a gestão ambiental.

\subsection{Gestão Ambiental na prática}

Ao longo deste artigo apresentamos as leis e diretrizes bases que regulamentam políticas públicas voltadas para os processos de gestão ambiental no Brasil. No entanto, com a intenção de sabermos como de fato essas políticas se empregam no dia-a-dia construímos um questionário para aplicar com algum especialista na área.

Inicialmente, entramos em contato com um profissional na área, explicando acerca do objeto de estudo em foco. Com a aceitação em participar da pesquisa, elaboramos então um roteiro prévio para submeter à análise. Aprovado o roteiro, organizamos o questionário e enviamos eletronicamente ao sujeito da pesquisa.

Adotamos o instrumento questionário, pois permite que as perguntas sejam respondidas sem a presença do pesquisador, oportunizando a economia de tempo para ambos os envolvidos (pesquisador e sujeito da pesquisa), conforme Marconi e Lakatos (1996) afirmam.

O questionário foi, então, sistematizado com perguntas abertas uma vez que, segundo Mattar (1996), permitem ao respondente ficar à vontade para usar suas próprias palavras, evitando a influencia de respostas predeterminadas.

Na ocasião, o sujeito desta pesquisa (ao qual iremos nos referir como MESQUITA, T. P. N.) é um ecólogo e tecnólogo em meio ambiente, mestre em bioecologia aquática, doutorando em ciência e engenharia do petróleo, consultor ambiental, foi subcoordenador do Núcleo de Licenciamento Ambiental de Parques Eólicos no RN, entre outras funções que acumula.

Para reflexão neste trabalho, realizamos cinco questões com alguns desdobramentos sobre as quais discorreremos. A primeira delas pedia que descrevesse o processo de formulação de políticas públicas de gestão ambiental e comentasse sobre sua participação nesse processo.

Em resposta, o ecólogo em questão introduziu sua fala discorrendo brevemente sobre o contexto de surgimento da inclusão do planejamento ambiental nas políticas públicas, citando a reunião em Estocolmo/1972 e o Relatório Nosso Futuro Comum/1987. A partir de então, fez a ponte com o presente, pontuando que o processo de formulação de políticas públicas inicia com a manifestação de interesses da sociedade civil organizada, adentrando as audiências públicas, até chegar às legislações. Nesse sentido, destacamos (da fala dele que se pauta na própria experiência) a participação social no processo de formulação das políticas como instrumento democratizante. E essa participação não deve se limitar a simples manifestação de interesses, mas sim colaborando nos processos de formação da agenda, construção do problema e dos instrumentos de intervenção até os processos de implementação e, sobretudo, de avaliação das políticas públicas, como nos diz Brasil (2007).

A importância dessa participação como elemento de exercício de cidadania é justificada pelos autores Brugué, Font e Gomà (2006, citados em BRASIL, 2007, p. 119) ao colocarem que é 
uma forma de superar déficits administrativos e políticos, bem como representa um processo de amadurecimento democrático.

Nesse contexto, estamos considerando a participação social sob as dimensões pública e política que constituem espaços de publicização de conflitos, de negociação de interesses distintos e de afirmação e construção de identidades coletivas, como explica Santos (2002, citado em BRASIL, 2007, p. 121). Assim, se torna instrumento de fortalecimento da sociedade civil.

Dentro dessa perspectiva, Brasil (2007, p. 119) pontua ainda que a participação social pode ocorrer como controle público, função educativa e integrativa e aprendizado social. Seria, por assim dizer, fruto de uma sólida educação ambiental, listada como objetivo da PNEA (lei no 9.795/99), pontuado no art. 5으, inciso X: incentivo à participação individual e coletiva, permanente e responsável, na preservação do equilíbrio do meio ambiente, entendendo-se a defesa da qualidade ambiental como um valor inseparável do exercício da cidadania. Isso nos remete ao que Loureiro (2008) prega:

O desafio para a consolidação de uma cidadania substantiva e direta reside na capacidade de publicizar as instituições formais, de estabelecer práticas democráticas cotidianas, de promover uma escola capaz de levar o aluno a refletir criticamente sobre seu ambiente de vida e de consolidar uma "cultura da cidadania", nos planos local, regional ou internacional, articulada aos processos de transformação sistêmica. (LOUREIRO, 2008, p. 75, grifo do autor).

O resultado de uma escolarização em que prevalece criticidade e engajamento na intervenção local para a transformação socioambiental é um ecossistema mais duradouro. Poderíamos arriscar dizer que, o respondente do questionário aplicado pode ser percebido como reflexo de uma formação crítica (congruente à proposta da instituição onde cursou a graduação em Tecnologia em Meio Ambiente/IFRN). Percebemos a influência dessa formação crítica ao comentar sobre sua postura diante do processo de construção de políticas públicas na esfera ambiental, pois citou que atuou tanto como cidadão comum, participando e opinando em audiências públicas, quanto auxiliando "tecnicamente, por meio da elaboração de zoneamento ambiental, programas e projetos socioambientais para municípios" (MESQUITA, T. P. N., 2014). Fazemos, então, uma ponte com a fala de Bárcena (2008) ao dizer:

O cidadão crítico e consciente é aquele que compreende, se interessa, reclama e exige seus direitos ambientais ao setor social correspondente e que, por sua vez, está disposto a exercer sua própria responsabilidade ambiental. Este cidadão, quando de organiza e participa na direção de sua própria vida, adquire poder político e uma capacidade de mudança coletiva. (BÁRCENA, 2008, apud LOUREIRO, 2008, p. 15).

Ficar de fora só reclamando, não é cidadania. É preciso se interessar, participar, se envolver na luta, "exercer sua própria responsabilidade ambiental", como diz Bárcena (2008) na fala citada acima.

Na sequência, perguntamos sobre a organização e estruturação dos sistemas de gestão ambiental, bem como seus responsáveis. Em resposta, o especialista respondente explicou que "um sistema de gestão ambiental é um conjunto de rotinas e procedimentos sistematizados e aplicados" no meio ambiente, por uma organização. Os seus responsáveis seriam, por 
consequência, "toda e qualquer organização que troca com o meio ambiente energia e matéria" (MESQUITA, T. P. N., 2014). De acordo com o especialista em questão, isso ocorre a partir de um processo sistemático: demandas socioambientais levam à Organização a necessidade de administrar adequadamente suas relações com o meio ambiente, criando para tanto, programas ambientais sistematizados.

Como caracterização das etapas para a estruturação desse sistema, o respondente definiu:

a) Planejamento - primeiro identifica-se e classifica os aspectos e impactos ambientais. Em segundo lugar, elegem-se as normas e legislações pertinentes, a serem cumpridas pela organização e, por último, estabelecem-se os objetos, metas e criam-se os programas ambientais.

b) Execução - a execução tem a seguinte sequência: obtenção dos recursos necessários, estabelecimentos das funções, responsabilidades e autoridades de cada um no processo; obtenção das competências, treinamentos e conscientização de cada um, estabelecendo uma boa comunicação interna, documentando e controlando cada um dos documentos.

c) Acompanhamento/monitoramento - através de auditorias internas, externas e programas contínuos de monitoramentos.

d) Avaliação - através de instrumentos de melhoria contínua como análises pela administração, análises de contingência, análises de não conformidades e ações corretivas. (MESQUITA, T. P. N., 2014).

Frente à discussão das etapas citadas pelo especialista que respondeu ao questionário aplicado, identificamos que o planejamento abarcaria a construção da agenda, juntamente com a formulação da política, fases definidas por CUNHA (2001).

A fase da agenda, crucial para a elaboração da política (disseminada na fala de MESQUITA, T. P. N. como parte da etapa de planejamento) constitui-se como espaço de reconhecimento dos problemas que chamam a atenção do governo e do cidadão. $E$, a formulação da política seria o processo de elaboração de alternativas de ação/intervenção de ordem pública em resposta a problemas que constem na agenda política.

A implementação que é a transformação da política formulada em programa, respeitandose as diretrizes expressas na legislação, conforme nos diz Cunha (2001), inicia no planejamento e se dilui na etapa de execução (como descreve MESQUITA, T. P. N., 2014).

As duas últimas etapas, monitoramento e avaliação, indispensáveis a qualquer política, sobretudo quando revestidas de ética, acompanham o processo de desenvolvimento da política. São fases que identificam o nível de alcance das metas, sua real aplicabilidade e as necessárias mudanças para o programa, que pressupõem novas decisões políticas.

Avançando um pouco mais, solicitamos no questionário a identificação das particularidades, problemas vivenciados e desafios encontrados no ramo das políticas públicas vinculadas à gestão ambiental quanto à cidade, estado e país.

O tecnólogo ambiental, respondente das questões pontuou que o que percebe é "um efeito em cascata da influência do federal para o estadual e deste para o municipal". O que de fato pode ser confirmado na Lei no 6.938/81 (PNMA), quando delibera: 
Art 5ㅇ - As diretrizes da Política Nacional do Meio Ambiente serão formuladas em normas e planos, destinados a orientar a ação dos Governos da União, dos Estados, do Distrito Federal, dos Territórios e dos Municípios no que se relaciona com a preservação da qualidade ambiental e manutenção do equilíbrio ecológico, observados os princípios estabelecidos no art. 2o desta Lei.

Parágrafo único - As atividades empresariais públicas ou privadas serão exercidas em consonância com as diretrizes da Política Nacional do Meio Ambiente. (BRASIL, 1981).

No tocante aos problemas vivenciados, MESQUITA, T. P. N. (2014) declarou que se relacionam à falta de recursos humanos e econômicos, bem como a inaplicação das legislações e falta de incentivos fiscais às organizações, além de escassez de um mercado consumidor que perceba a questão ambiental como um diferencial competitivo.

Isso nos remete à Krause (1997), quando nos diz que:

[...] a complexidade da gestão ambiental está em compreender a transição revolucionária e a mudança de paradigma em movimento acelerado. [...] está em reconhecer [...] que a viabilidade da efetiva ação transformadora tem como obstáculo as contradições que colocam frente a frente a nova racionalidade em formação e a predominante racionalidade de acumulação a qualquer preço, arraigada nos sistemas de produção e legitimadora dos processos políticos. (KRAUSE 1997, apud CAVALCANTI, 1997, p.17).

Em relação aos desafios encontrados, o respondente denuncia e expõe como angústia "barreira fiscal, crédito não direcionado para finalidades ambientais e mercado consumidor ignorante as questões ambientais". Isso ocorre mesmo fazendo parte da Lei no 6.938/81, o art. 17 que estabelece que os recursos arrecadados com a Taxa de Controle e Fiscalização Ambiental (TCFA), sob a responsabilidade do IBAMA, terão utilização restrita em atividades de controle e fiscalização ambiental. Percebemos com isso, como a prática se distancia do discurso, mesmo que este seja expresso no texto da lei.

A fala do tecnólogo nos permite também refletir acerca da fragilidade fiscalizadora, tanto dos órgãos competentes quanto da sociedade civil organizada, principalmente. Permeando essa fragilidade está a inexistência da ética cidadã comprometida com o meio ambiente.

Além dessa percepção, vislumbramos ainda a fatídica carência da educação ambiental subliminar a todos os desafios (citados por MESQUITA,T. P. N.), principalmente, justificando a ignorância do mercado consumidor. Entendemos essa ignorância como uma parte estrutural do processo de desconstrução e reconstrução do saber ambiental que não atingiu a todos, embora tenha espaço para sua expansão em todos os níveis e modalidades de ensino, sobretudo na Educação Profissional. Isso nos permite lembrar o que Leff (2010) escreve a esse respeito.

O saber ambiental nasce de uma nova ética e de uma nova epistemologia, na qual se fundem conhecimentos, se projetam valores e se internalizam saberes. Para aprender a aprender a complexidade ambiental é necessário desaprender e dessujeitar-se dos conhecimentos concebidos. O saber ambiental é um questionamento sobre as condições ecológicas da sustentabilidade e as bases sociais da democracia e da justiça; é uma construção e comunicação de saberes que colocam em tela o juízo das estratégias de poder e os efeitos de dominação 
que se geram através de formas de detenção, apropriação e transmissão de conhecimentos. (LEFF, 2010, p.8).

Esse processo de reconstrução pelo qual o saber ambiental perpassa, encontra alicerce também na educação ambiental, proposta pelas DCNEA que atende a PNEA. E a Educação Ambiental, por sua vez, é base para a gestão ambiental (compreensão essa já apresentada anteriormente nesse artigo), identificada na fala do especialista ao ser solicitado a comentar a relação existente entre gestão ambiental e educação ambiental.

A educação ambiental é fundamental para obtermos, a longo prazo, uma sociedade mais consciente e sensível sobre as questões ambientais. É através desse processo que a sociedade passa a entender que suas ações sobre o meio ambiente trazem consequências diretas sobre nós mesmos. Esse processo de sensibilização gera naturalmente necessidades básicas como gerir os resíduos sólidos, uso consciente de energia e água, utilização de energias mais limpas e preservação de recursos e funções ambientais indispensáveis para a qualidade de vida e bem estar da população humana. Com o tempo, certamente essas ações pontuais passarão a ser consideradas Gestão Ambiental, pois o componente sistemático será necessário para melhor organização e aplicação em escalas cada vez maior. (MESQUITA, T. P. N., 2014).

Características de sensibilização essa aos quais os objetivos de formação de profissionais na área se submetem.

Para concluir o questionário, perguntamos sobre a percepção pessoal do sujeito respondente acerca das políticas públicas voltadas para a Educação Profissional na área de Gestão Ambiental, no tocante aos avanços, carências e possíveis sugestões.

Com relação aos avanços, MESQUITA, T. P. N. (2014) identificou "a criação de vários cursos de graduação e pós-graduação na área ambiental", o que atende a proposta estabelecida na PNEA, em seu art. 2으. já citado, ao mencionar que a Educação Ambiental deve estar presente em todos os níveis e modalidades de ensino. No tocante às carências, relatou que se referem aos "recursos humanos e financeiros, de consciência e pouca aplicação legal” (MESQUITA, T. P. N., 2014), previstos na PNEA e na PNMA. E como sugestão defendeu a "implantação de disciplinas no ensino básico e fundamental sobre meio ambiente", além de "maior rigor e participação do Ministério Público nos órgãos ambientais, maior popularização das mídias de massas sobre empresas, projetos, programas que fazem a diferença na área ambiental", bem como a elevação de "incentivos fiscais e políticas públicas que beneficiem de alguma forma aqueles que são diferentes em suas condutas na área ambiental” (MESQUITA, T. P. N., 2014).

Frente a essa última fala, compreendemos sua sugestão de implantação de disciplinas sobre meio ambiente como elemento de fortalecimento e solidificação da Educação Ambiental, desde o processo de escolarização básica. Porém, até a presente data, isso ainda não é possível. Voltando à Lei no 9.795/99, no art. 10, § 1으os diz que a educação ambiental não deve ser implantada como disciplina específica no currículo de ensino. A temática pode e deve ser adotada como elemento transversal para perpassar por todas as componentes curriculares, ficando facultado aos cursos profissionalizantes, graduações e pós-graduações a inserção dessa nova componente, a depender das finalidades do curso ofertado. 
No caso dos Instituto Federal de Educação, Ciência e Tecnologia do Rio Grande do Norte (IFRN), alguns dos cursos técnicos que atendem a perspectiva de disciplinas específicas a explorar elementos característicos da temática em estudo são: Controle Ambiental, com disciplinas como ecotoxicologia, impactos ambientais, cartografia ambiental, direito ambiental, gestão ambiental, poluição e controle ambiental, vigilância sanitária e ambiental; Geologia, com a disciplina geologia ambiental; Mineração, com a disciplina mineração e meio ambiente; Petróleo e Gás, com a disciplina impactos ambientais na indústria; Segurança do Trabalho, com a disciplina controle ambiental, entre outros cursos técnicos. Quanto aos cursos tecnólogos, citamos em especial o de Gestão Ambiental com disciplinas como: cidadania, ética e meio ambiente; segurança, meio ambiente e saúde; técnicas de educação ambiental; planejamento ambiental, entre tantas outras disciplinas intimamente envolvidas com a temática.

Diante do contexto, destacamos e reafirmamos a necessidade de maior rigor da participação do Ministério Público nos órgãos ambientais, como sugeriu o ecólogo, bem como defendemos ainda a necessária ampliação da participação da sociedade civil organizada no processo fiscalizador.

Quanto à sugestão final apresentada, acerca dos "incentivos fiscais e políticas públicas que beneficiem de alguma forma aqueles que são diferentes em suas condutas na área ambiental", recordamos a proposta que Cavalcanti (1999) também faz nesse sentido: "a política de governo para a sustentabilidade deve conter medidas para estimular aqueles setores que efetivamente adicionem valor, contribuindo menos para a depleção e degradação." (CAVALCANTI, 1999, p.35).

Uma proposta como essa de contrapartida pela preservação e/ou conservação ambiental atrairia por vias fiscais mais interessados a investir em medidas ecologicamente corretas, evitandose estímulos à destruição de ecossistemas. Na atualidade, já temos conhecimento de prêmios desse tipo (citamos, por exemplo, o Prêmio Boas Práticas em Gestão Ambiental Urbana, organizado pelo MMA, a partir de 2010), mas ainda escassos diante da grandeza de ações devastadoras dos biomas existentes. As turmas da graduação em Tecnologia em Gestão Ambiental poderiam ser destaque nesse sentido, tendo em vista os frutos potenciais de disciplinas como Planejamento Ambiental ou Técnicas de Educação Ambiental, por exemplo. No entanto, não há destaque para isso. Práticas ecologicamente corretas ainda hoje não têm evidência na mídia já que não foi percebida sua conveniência até aqui. Portanto, não se pode parar. Ao contrário disso: é preciso fazer mais!

\section{CONSIDERAÇÕES FINAIS}

A crise ambiental, apesar de ter começado em outros tempos, é responsabilidade nossa, pois também permanece e avança no presente. Se não pararmos para pensar sobre ela e agir efetivamente mudando posturas de ser e estar no mundo, apressaremos o fim de todos.

Foi partindo dessa compreensão que em 1972 foi organizada a Conferência de Estocolmo, com a reunião de vários países do mundo, para se discutir o conceito de ecodesenvolvimento. Desse ponto para frente, as discussões se multiplicaram e a temática, aos poucos, foi ganhando força. Alguns relutando ou ignorando os fatos, uns fingindo e maquiando, outros aceitando e investindo em mudanças. 
Chegamos ao século XXI e percebemos que pouco mudou. Novas redações em leis, novos programas criados, incrementos orçamentários, maior rigidez nos papéis... mas, na prática, nem tudo se aplica - foi o que vimos aqui.

Percebemos ainda como a Política Nacional do Meio Ambiente (de 1981) está imbricada com o Fundo Nacional do Meio Ambiente (de 1989), o Programa Nacional de Educação Ambiental (de 1993) e a Política Nacional de Educação Ambiental (de 1999). Embora datem de períodos distintos (às vezes até anacrônicos), todos se articulam na busca pela gestão dos recursos naturais para a preservação da biodiversidade e manutenção da vida no planeta, se valendo da educação ambiental como elemento estratégico. Porém, ainda falta muito, do que está nos documentos bases das regulamentações e diretrizes legais, a ser consolidado na prática.

Um dos meios de conseguirmos que o que está na lei se aplique verdadeiramente na prática por um desenvolvimento sustentável a fim de assegurarmos a manutenção da vida no planeta, preservando os recursos naturais, é formando sujeitos histórico-sociais, crítico e politicamente ativos para isso. Faz-se então urgente iniciar essa formação pela Educação Básica, englobar a Educação de Jovens e Adultos, alicerçar a Educação Profissional e se prolongar pelo Ensino Superior. Essa urgência se dá pelo fato de que gestão ambiental pressupõe políticas públicas para si e também para a educação ambiental - e ambas não se fazem sem consciência ética, ecológica e planetária. Essa consciência só se atinge/constrói quando atribuímos sentido ao que aprendemos no campo teórico, exercendo na prática novas vivências, engajados na transformação da realidade local, para afetar o regional e, por consequência, contaminar o global. Assim sendo, onde esses sujeitos adentrarem irão investir na conquista por um ambiente ecologicamente equilibrado.

Ao final dessa esfera de reflexões, identificamos que as políticas públicas voltadas para área ambiental se configuram como um instrumento de gestão ambiental, enquanto a educação (inclusive a profissional e superior, que poderão formar profissionais para atuar na área), é instrumento estratégico para gestão ambiental. Consideramos, portanto, que educação (sobretudo a Educação Profissional, por sua competência de formar cidadãos também para atuação específica na área), políticas públicas e gestão ambiental estão intimamente imbricados.

\section{REFERÊNCIAS BIBLIOGRÁFICAS}

1. AZEVEDO, Janete Lins de. Notas sobre a análise da gestão da educação e da qualidade do ensino no contexto das políticas educativas. RBPAE, Porto Alegre, v.27, n.3, p. 361-588, set./dez. 2011.

2. BÁRCENA, Alicia. Cidadania Ambiental. In: GUTIÉRREZ, Francisco; PRADO, Cruz. Ecopedagogia e cidadania planetária. 4. ed. São Paulo: Cortez/Instituto Paulo Freire, 2008. Apresentação, p.13-19. (Guia da Escola Cidadã; v. 3).

3. BRANCO, Sandra. Educação ambiental: metodologia e prática de ensino. Rio de Janeiro: Dunya, 2003. 100p.

4. BRASIL, Flávia de Paula Duque. A participação cidadã nas políticas sociais e na gestão de programas e projetos: potenciais e desafios. In: FAHEL, Murilo; NEVES, Jorge Alexandre B. (orgs.). Gestão e avaliação de políticas sociais no Brasil. Belo Horizonte: PUC/MINAS, 2007.

5. BRASIL. Congresso Nacional. Lei $n=6.938$, de 31 de agosto de 1981. Dispõe sobre a Política Nacional do Meio Ambiente, seus fins e mecanismos de formulação e aplicação. Brasília, DF, 
1981.

6. BRASIL. Congresso Nacional. Lei no 7.797, de 10 de julho de 1989. Cria o Fundo Nacional de Meio Ambiente Brasília, DF, 1989.

7. BRASIL. Congresso Nacional. Lei $n=9.394$, de 20 de dezembro de 1996. Estabelece as diretrizes e bases da educação nacional. - 6. ed. - Brasília : Câmara dos Deputados, Edições Câmara, 2011.

8. BRASIL. Congresso Nacional. Lei $\mathbf{n}^{\circ}$ 9.795, de 27 de abril de 1999. Dispõe sobre a educação ambiental, institui a Política Nacional de Educação Ambiental Brasília, DF, 1999.

9. BRASIL. Ministério da Educação. Conselho Nacional de Educação. Resolução no 2 de 15 de junho de 2012. Estabelece as Diretrizes Curriculares Nacionais para a Educação Ambiental. Brasília: CNE. Disponível em: http://conferenciainfanto.mec.gov.br/images/pdf/diretrizes.pdf Acesso em 23 jun 2014.

10. BRASIL. Ministério do Meio Ambiente. Secretaria Executiva. Diretoria de Educação Ambiental. Órgão Gestor da PNEA e seu Comitê Assessor: 2003/2006. Brasília: MMA, 2003. Disponível em: http://www.mma.gov.br/estruturas/educamb/_arquivos/cad_02.pdf Acesso em 23 jun 2014.

11. BRASIL. Ministério do Meio Ambiente. Diretoria de Educação Ambiental. Programa Nacional de Educação Ambiental. 3. ed. Brasília: MMA, 2005.

12. BRAVERMAN, Harry. Trabalho e força de trabalho. IN:_ Trabalho e capital monopolista: a degradação do trabalho no século XX. 3. ed. Trad. Nathanael C. Caixeiro. Rio de Janeiro: Zahar, 1977. (Cap. 1, p.49 a 134).

13. CUNHA, Elenice Machado da. Regra e realidade na constituição do SUS municipal: implementação da NOB 96 em Duque de Caxias. [Mestrado] Fundação Oswaldo Cruz, Escola Nacional de Saúde Pública; 2001. 144 p.

14. GUTIÉRREZ, Francisco; PRADO, Cruz. Novas Práticas. In: _ Ecopedagogia e cidadania planetária. 4. ed. São Paulo: Cortez/ Instituto Paulo Freire, 2008. Cap. 3, p.47-55. (Guia da Escola Cidadã; v. 3).

15. IFRN. Projeto Pedagógico do Curso Superior de Tecnologia em Gestão Ambiental na modalidade presencial. $2012 . \quad$ Disponível em: http://portal.ifrn.edu.br/campus/natalcentral/cursos/cursos-de-graduacao/gestaoambiental.html Acesso em 09 jul 2014.

16. LANNA, Antônio Eduardo Leão. Gerenciamento de bacia hidrográfica: aspectos conceituais e metodológicos. Brasília: Instituto Brasileiro do Meio Ambiente e dos Recursos Naturais Renováveis, 1995. 171 p.

17. LEFF, Enrique (coord.). A complexidade ambiental. 2. ed. São Paulo: Cortez, 2010. Tradução de Eliete Wolff.

18. LOUREIRO, Carlos Frederico Bernardo. Educação ambiental e movimentos sociais na construção da cidadania ecológica e planetária. In:_Educação Ambiental: repensando o espaço da cidadania. 4. ed. São Paulo: Cortez, 2008. p. 69-98.

19. MARCONI, Marina de Andrade; LAKATOS, Eva Maria. Técnicas de pesquisa: planejamento e execução de pesquisas, amostragens e técnicas de pesquisas, elaboração, análise e interpretação de dados. 3. ed. São Paulo: Atlas, 1996. 
20. MATTAR, Fauze Najib. Pesquisa de marketing: edição compacta. São Paulo: Atlas, 1996.

21. PINTO, Anna Florência de Carvalho Martins. Metodologia do trabalho científico: planejamento, estrutura e apresentação de trabalhos acadêmicos segundo as normas da ABNT. Belo Horizonte: Pontifícia Universidade Católica de Minas Gerais, 2010, 99 p.

22. SORRENTINO, Marcos. Desenvolvimento sustentável e participação: algumas reflexões em voz alta. In: LOUREIRO, Carlos Frederico Bernardo; LAYRARGUES, Philippe Pomier; CASTRO, Ronaldo Souza de (orgs.). Educação Ambiental: repensando o espaço da cidadania. 4. ed. São Paulo: Cortez, 2008. p. $15-21$ 